\title{
Operative classification of thromboembolic disease determines outcome after pulmonary endarterectomy
}

\author{
Patricia A. Thistlethwaite, $\mathrm{MD}, \mathrm{PhD}^{\mathrm{a}}$ \\ Makato Mo, MD \\ Michael M. Madani, MD \\ Reena Deutsch, $\mathrm{PhD}^{\mathrm{b}}$ \\ Daniel Blanchard, $\mathrm{MD}^{\mathrm{C}}$ \\ David P. Kapelanski, MDa \\ Stuart W. Jamieson, MB, FRCS ${ }^{a}$
}

\footnotetext{
From the Divisions of Cardiothoracic Surgery, ${ }^{\mathrm{a}}$ Biostatistics, ${ }^{\mathrm{b}}$ and Cardiology, ${ }^{\mathrm{c}}$ University of California, San Diego, Calif.

Received for publication Dec 13, 2001; revisions requested March 25, 2002; revisions received June 10, 2002; accepted for publication June 13, 2002.

Address for reprints: Patricia A. Thistlethwaite, MD, PhD, Division of Cardiothoracic Surgery, University of California, San Diego, 200 West Arbor Dr, San Diego, CA 92103-8892 (E-mail: pthistlethwaite@ ucsd.edu).

J Thorac Cardiovasc Surg 2002;124: $1203-11$

Copyright () 2002 by The American Association for Thoracic Surgery

$0022-5223 / 2002 \$ 35.00+0 \quad \mathbf{1 2 / 1 / 1 2 7 3 1 3}$

doi:10.1067/mtc.2002.127313
}

Objective: We sought to determine whether type and location of thromboembolic disease in the pulmonary vascular tree predicts the hemodynamic result and clinical outcome in patients undergoing pulmonary endarterectomy.

Methods: From 1998 to 2000, 202 patients with pulmonary hypertension and pulmonary vascular resistance ranging from 194 to 2950 dynes-s-cm ${ }^{-5}$ underwent pulmonary endarterectomy. Preoperative and postoperative tricuspid valve function, pulmonary artery pressure, and pulmonary vascular resistance were determined by means of transthoracic echocardiography and measurements with a Swan-Ganz catheter (Edwards Lifesciences, Irvine, Calif), respectively. Patients underwent intraoperative classification of thromboembolism as follows: type 1 (76 patients), fresh thrombus in the main-lobar pulmonary arteries; type 2 (81 patients), intimal thickening and fibrosis proximal to the segmental arteries; type 3 (38 patients), disease within distal segmental arteries only; and type 4 (7 patients), distal arteriolar vasculopathy without visible thromboembolic disease.

Results: Overall perioperative mortality was $4.5 \%$ (9/202 patients). By means of univariate analysis, patients with type 3 or 4 disease (distal pulmonary vasculopathy) had more residual postoperative tricuspid regurgitation $(P<.0001)$, higher postoperative pulmonary artery systolic pressure $(P<.0001)$, and greater postoperative pulmonary vascular resistance $(P<.0001)$ compared with that seen in patients with type 1 or 2 disease, in whom thromboembolic disease was more surgically accessible. Factors such as severity of preoperative tricuspid regurgitation, patient age, and circulatory arrest time had no correlation with postoperative hemodynamic improvement. Patients with distal thromboembolic disease (type 3-4) had higher perioperative mortality, required longer inotropic support, and had longer hospital stays compared with patients with type 1 or 2 thromboembolic disease.

Conclusion: The degree of improvement in pulmonary hypertension and tricuspid regurgitation after pulmonary endarterectomy is determined by the type and location of pulmonary thromboembolic disease. Classification of thromboembolism is useful for predicting patient outcome after pulmonary endarterectomy.

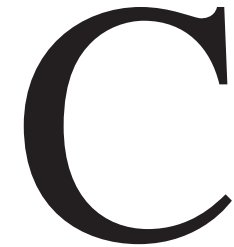

hronic thromboembolic pulmonary hypertension is a rare disease that is estimated to result in fewer than $1 \%$ of all cases of acute pulmonary embolism. ${ }^{1,2}$ Several mechanisms have been postulated to cause chronic pulmonary hypertension after an acute embolic event. These include a recurrence of embolism reported after $2.5 \%$ to $7 \%$ of adequately treated pulmonary embolic events, ${ }^{3}$ in situ thrombus propagation into branch pulmonary vessels, ${ }^{4}$ and failure to resolve the 
initial embolus, leading to large- and small-vessel vasculopathy. ${ }^{5}$ In the proximal pulmonary arterial tree, unresolved pulmonary emboli cause vascular obstruction by means of 2 mechanisms: (1) by direct occlusion of the vessel lumen and (2) by inducing secondary endothelial changes of cellular hyperplasia, webbing, and incomplete clot remodeling. ${ }^{6,7}$ In a subset of patients with chronic thromboembolism, the terminal pulmonary arterioles and capillaries also manifest a pathologic process similar to that seen in primary pulmonary hypertension, whereby these small vessels become excessively thickened by muscular hypertrophy and hyperplasia, leading to eventual occlusion. ${ }^{8}$

A spectrum of these acute and chronic pulmonary vascular changes are encountered at the time of pulmonary endarterectomy for chronic pulmonary hypertension. Although pulmonary endarterectomy is now a widely acceptable operation for thromboembolic pulmonary hypertension with perioperative mortality rates as low as $5.3 \%, 9^{9}$ little is known about the anatomic factors that affect surgical outcome. In specific, the influence of pulmonary vascular changes, such as acute or chronic embolism, location of thromboembolic material in the pulmonary arterial tree, and the degree of distal small-vessel vasculopathy on the outcome of pulmonary endarterectomy, has not been established.

This study was designed as a prospective analysis of patients undergoing isolated pulmonary endarterectomy at our institution over a 2-year period to examine whether anatomic intravascular factors, such as location, extent, and type of clot, would predict postoperative hemodynamic function, resolution of tricuspid regurgitation (TR), and improvement in pulmonary vascular resistance. A classification scheme for thromboembolism has previously been reported. ${ }^{7}$ We validate that this classification system allows for the prediction of early patient outcome after pulmonary endarterectomy.

\section{Methods \\ Patient Selection}

We identified and followed 202 patients with complete medical records (101 men and 101 women; mean age, 54.7 years; range, 18-76 years) from the University of California, San Diego, Pulmonary Endarterectomy Registry, who underwent surgical intervention between July 1998 and December 2000. This prospectively collected and validated database provides comprehensive descriptions of clinical and surgical characteristics of most patients undergoing pulmonary endarterectomy at our institution since 1996. During the time period of this study, 290 patients underwent pulmonary endarterectomy alone or in conjunction with foramen ovale closure, and 27 patients underwent pulmonary endarterectomy combined with other cardiac operations. Patients undergoing concomitant coronary revascularization or valve repair-replacement at the time of pulmonary endarterectomy were excluded from this study. The selection criteria for patients undergoing pulmo- nary endarterectomy included (1) New York Heart Association (NYHA) class III or IV, (2) pulmonary vascular resistance of greater than 200 dynes-s- $\mathrm{cm}^{-5}$, (3) absence of significant noncardiac comorbid disease, and (4) appearance of chronic thrombi on pulmonary angiogram. Preoperative inotropic support included dopamine, epinephrine, or both in 5 patients and intra-aortic balloon counterpulsation in 1 patient. Three patients were ventilator dependent before the operation. Oral medications at the time of the operation included loop diuretics (198/202 [98.0\%] patients), metolazone (45/202 [22.3\%] patients), digoxin (37/202 [18.3\%] patients), angiotensin-converting enzyme inhibitor (107/202 [53.0\%] patients), $\beta$-blocker (15/202 [7.4\%] patients), and warfarin (98/202 [48.5\%] patients). All patients underwent preoperative insertion of an inferior vena caval Greenfield filter.

\section{Surgical Classification and Hemodynamic Measurement}

Our surgical method of pulmonary endarterectomy has been previously described..$^{10}$ Two surgeons performed all operations on cardiopulmonary bypass with a period of circulatory arrest ranging from 12 to 73 minutes (mean, 31.0 minutes) for the distal-most portion of the endarterectomy procedure for both lungs. In this study we wished to validate, in a prospective fashion, whether thrombus type and location described in our classification system was a predictor of early postoperative outcome. To this end, during the operation, thromboembolic disease was visualized and classified into one of 4 groups: type 1 (76 patients), fresh (acute) thrombus in the main-lobar pulmonary arteries; type 2 (81 patients), intimal thickening and fibrosis with or without organized thrombus proximal to segmental arteries; type 3 (38 patients), fibrosis, intimal webbing, and thickening with or without organized thrombus within distal segmental arteries only; and type 4 (7 patients), microscopic distal arteriolar vasculopathy without visible thromboembolic disease (Figure 1). At the time of surgery, photographs of each endarterectomy specimen were taken and incorporated into the patient's medical record and into the University of California, San Diego, Pulmonary Endarterectomy Database for blinded review. Forty-one patients manifested different disease types in the right and left pulmonary vasculature. For these patients, the thromboembolism classification was noted for each side. When there was discrepancy between disease type between the right and left sides, the more proximal thromboembolism classification was used for statistical analysis in this study. Eighty patients ( 31 with type 1 disease, 30 with type 2 disease, 16 with type 3 disease, and 3 with type 4 disease) underwent simultaneous closure of a secondary foramen ovale opened by means of increased right atrial pressures.

Severity of TR was graded by transthoracic echocardiography as mild to severe $(1+-4+)$ on the basis of a composite analysis of measurements of jet area, ratio of TR jet area to right atrial area, and pulsed-wave Doppler interrogation of the hepatic veins. ${ }^{11} \mathrm{~A}$ TR jet area that was limited to the immediate atrial aspect of the tricuspid valve and filled less than $33 \%$ of the right atrium (RA) was defined as $1+$. A jet filling $33 \%$ to $66 \%$ of the RA was defined as $2+$, whereas a $3+$ TR jet area was defined as filling more than $66 \%$ of the RA. A $4+$ TR jet both filled greater than $66 \%$ of the RA and caused systolic flow reversal in the hepatic veins. Maximal regurgitant jet areas were chosen for all measurements. Continu- 


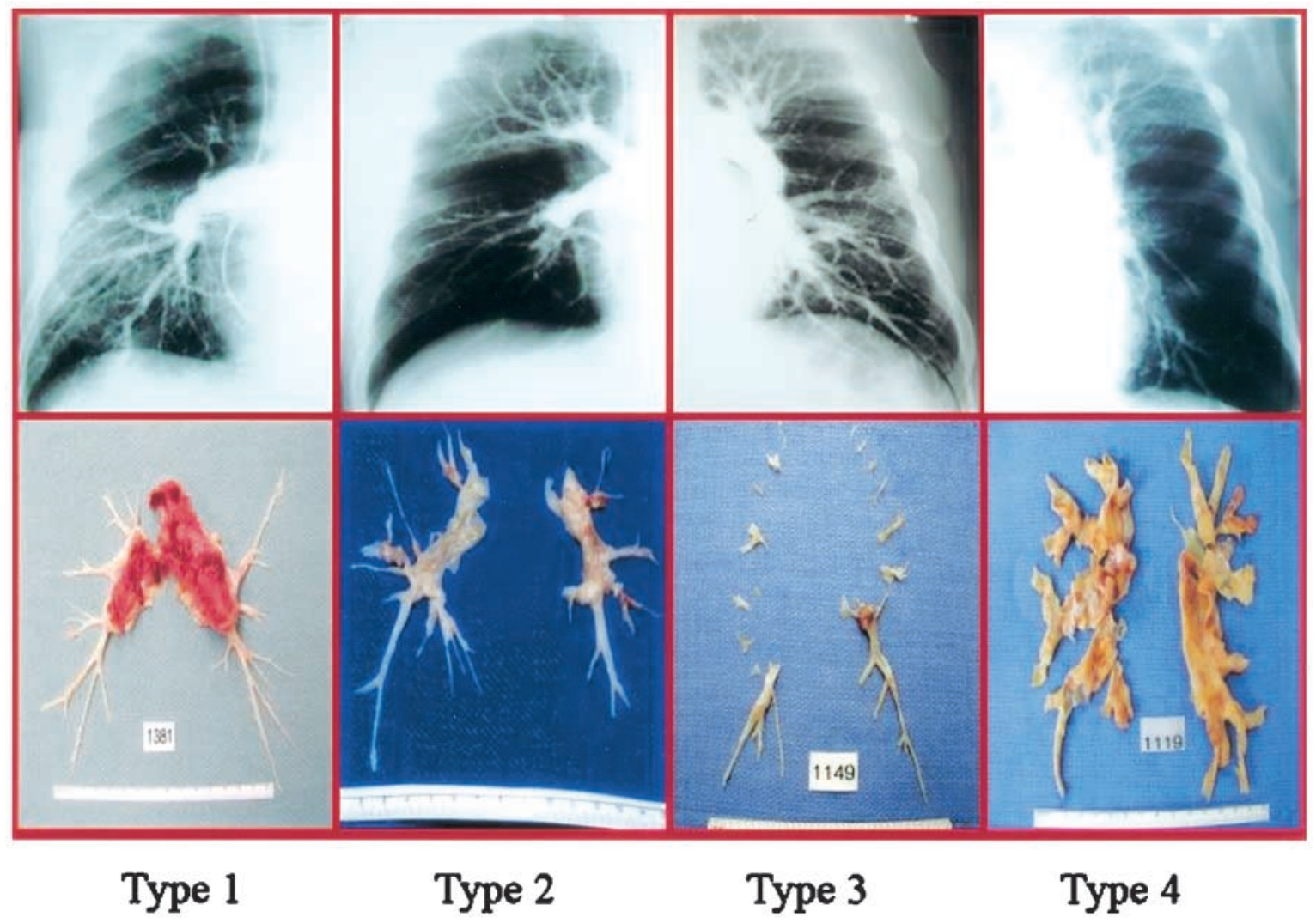

Figure 1. Pulmonary angiograms and corresponding specimens removed at the time of pulmonary endarterectomy: type 1 disease, fresh thrombus in main-lobar arteries (note abrupt cutoff of branches and lack of filling to the periphery on angiography; type 2 disease, organized thrombus and intimal thickening proximal to segmental arteries (note poststenotic dilatation of the lower lobar vessel and lack of filling to the periphery on angiography); type 3 disease, intimal thickening-fibrosis in distal segmental arteries, with surgical plane raised at each segmental level; type 4 disease, distal arteriolar vasculopathy with removal of normal intimal layer and no intraluminal disease.

ous-wave Doppler interrogation of TR jet velocity was performed in parasternal, apical, and subcostal imaging positions. The maximal velocity obtained was identified as peak TR velocity and was used to calculate the peak gradient between the right ventricle and the RA through the modified Bernouilli equation. ${ }^{12}$ Two-dimensional and Doppler echocardiography was performed by an echocardiographer with specific expertise in pulmonary hypertension using a Hewlett-Packard (Andover, Mass) Sonos 5500 echocardiography unit with broadband 2-dimensional Doppler transducers. Confirmatory blind Doppler assessment of peak TR velocity with a Pedoff continuous-wave probe was also performed in all patients.

Tricuspid valve morphology was evaluated both preoperatively and postoperatively in the apical 4-chamber, subcostal, parasternal short-axis view and modified parasternal long-axis (right atrial/ right ventricular) views to differentiate functional from organic TR. Functional TR (which accounted for all cases of TR in the study group) was defined as a lack of leaflet coaptation or failure of the valve leaflets to reach the plane of the tricuspid anulus during systole without evidence of structural abnormalities. Organic TR, defined as the presence of valvular doming or thicken- ing, flail valvular chordae, or ruptured papillary muscle, was not seen in any patient in this study.

Preoperative hemodynamics were assessed 3.3 months to 1 day before the operation by means of right heart catheterization (195 patients on an elective outpatient basis and 7 patients on an urgent inpatient basis). Left heart catheterization with coronary angiography was performed for all patients greater than 55 years of age. Postoperative hemodynamic measurements were made, with each patient weaned from inotropic and vasodilator support before Swan-Ganz line (Edwards Lifesciences, Irvine, Calif) removal 1 to 14 days (mean, 2.1 days) after the operation. Screening postoperative transthoracic echocardiography was performed 48 hours before hospital discharge (mean, 10.8 days after the operation) for each patient.

\section{Statistical Methods}

Duration of times were summarized as medians, and other continuous variables were reported as means \pm SD. Categoric variables were expressed as numbers and percentages. Global comparisons among thromboembolism classifications were performed by using 1-way analyses of variance with transformations when needed, 
TABLE 1. Preoperative patient characteristics

\begin{tabular}{|c|c|c|c|c|c|}
\hline \multirow[b]{2}{*}{ Variable } & \multicolumn{4}{|c|}{ Thromboembolism classification group } & \multirow[b]{2}{*}{$P$ value } \\
\hline & $\begin{array}{c}1 \\
(n=76)\end{array}$ & $\begin{array}{c}2 \\
(n=81)\end{array}$ & $\begin{array}{c}3 \\
(n=38)\end{array}$ & $\begin{array}{c}4 \\
(n=7)\end{array}$ & \\
\hline Age (y) & $51.0 \pm 15.1$ & $48.3 \pm 13.3$ & $48.3 \pm 13.4$ & $47.1 \pm 20.5$ & .605 \\
\hline Male sex $(\%)$ & $38(50.0)$ & $32(39.5)$ & $18(47.4)$ & $3(42.9)$ & .607 \\
\hline \multicolumn{6}{|l|}{ Pulmonary artery pressure $(\mathrm{mm} \mathrm{Hg})$} \\
\hline Systolic & $78.3 \pm 17.9$ & $80.2 \pm 19.1$ & $73.4 \pm 17.5$ & $71.3 \pm 15.8$ & .216 \\
\hline Diastolic & $32.5 \pm 9.6$ & $31.0 \pm 9.3$ & $32.1 \pm 11.3$ & $33.3 \pm 11.6$ & .773 \\
\hline Pulmonary vascular resistance (dynes-s-cm ${ }^{-5}$ ) & $911.1 \pm 436.5$ & $805.3 \pm 370.1$ & $902.8 \pm 504.1$ & $1015.1 \pm 481.7$ & .310 \\
\hline Cardiac index (L/min) & $3.01 \pm 0.37$ & $3.14 \pm 0.54$ & $2.98 \pm 0.48$ & $2.87 \pm 0.57$ & .150 \\
\hline Tricuspid regurgitant jet (M/s) & $4.36 \pm 0.74$ & $4.27 \pm 0.72$ & $4.25 \pm 0.87$ & $4.44 \pm 0.44$ & .772 \\
\hline $\mathrm{PaO}_{2}$ & $77 \pm 15.9$ & $72 \pm 20.7$ & $68 \pm 18.4$ & $74 \pm 14.4$ & .420 \\
\hline $\mathrm{FEV}_{1}$ & $2.16 \pm 0.21$ & $2.09 \pm 0.30$ & $2.10 \pm 0.33$ & $2.20 \pm 0.37$ & .227 \\
\hline Hematocrit $(\%)$ & $37.7 \pm 5.2$ & $37.8 \pm 4.6$ & $38.1 \pm 2.8$ & $37.6 \pm 3.5$ & .923 \\
\hline \multicolumn{6}{|l|}{ NYHA class } \\
\hline I & $1(1.3)$ & $0(0)$ & $0(0)$ & $0(0)$ & \\
\hline II & $28(36.8)$ & $27(33.3)$ & $13(34.2)$ & $2(28.6)$ & \\
\hline III & $41(54.0)$ & $48(59.3)$ & $22(57.9)$ & $4(57.1)$ & \\
\hline IV & $6(7.9)$ & $6(7.4)$ & $3(7.9)$ & $1(14.3)$ & \\
\hline
\end{tabular}

Data are shown as mean \pm SD or number (percentage).

$F E V_{\text {, }}$ Forced expiratory volume in 1 second.

Kruskal-Wallis tests, and Fisher-Freeman-Halton exact tests. Post hoc comparisons were performed by using the Tukey honestly significant difference tests. Student $t$ tests and Wilcoxon rank sum tests were used to test the relationship of potential predictors with outcome measures. TR, an ordinal categoric outcome measure, was treated as a continuous variable because of its assumed reflection of an underlying continuous distribution. $P$ values are reported for all statistical tests. Data were analyzed with JMP and SAS (Version 4.0.4 and Version 8, respectively; SAS Institute Inc, Cary, NC) and Minitab (Release 13.3; Minitab Inc, State College, Pa) software.

\section{Results}

All 202 patients in this study underwent bilateral pulmonary endarterectomy. Characteristics of patients at the time of operation for each thromboembolism classification group are detailed in Table 1 . The 4 patient groups were similar with respect to age, preoperative pulmonary artery pressures, pulmonary vascular resistance, and tricuspid regurgitant velocity. There was no statistically significant difference in the mean preoperative cardiac output or percentage of patients with NYHA functional class IV symptoms among the 4 groups. A larger proportion of pulmonary endarterectomy patients with type 1 or 2 disease had a previous history of deep venous thrombosis $(29.3 \%)$ or pulmonary embolism (56.3\%) than patients with more distal pulmonary arterial disease (groups 3 and 4), who had a $22.7 \%$ history of deep venous thrombosis and $40.9 \%$ incidence of preoperative pulmonary embolism.

There were significant differences between patients with type 1 and 2 disease (proximal arterial clot-vasculopathy) compared with patients with type 3 and 4 disease (segmen- tal artery or distal arteriolar vasculopathy) with respect to a decrease in tricuspid regurgitant velocity $(P<.0001)$ and downgrading of TR after pulmonary endarterectomy $(P<$ .0001 , Figure 2). Overall, patients with more proximal thromboembolic disease had a trend toward greater improvement in all measured components of TR, including tricuspid valve annular diameter, leaflet coaptation, and regurgitant jet area after the operation compared with patients with segmental artery and distal small-vessel vasculopathy.

Table 2 presents the mean change between preoperative and postoperative hemodynamic parameters of pulmonary artery pressure, pulmonary vascular resistance, right ventricular systolic pressure, and cardiac index among the 4 patient classification groups. Postoperative hemodynamic measurements were made with the patients weaned from all inotropic and vasodilator support just before Swan-Ganz line removal. There was significant difference between the mean diminution in pulmonary artery systolic pressure and the mean decrease in pulmonary vascular resistance between patients with proximal disease (groups 1 and 2) compared with patients with distal disease (groups 3 and 4, $P<$.0001). Patients undergoing pulmonary endarterectomy for fresh clot or intimal thickening-fibrosis in the main or lobar pulmonary arteries (groups 1 and 2) had, in general, a greater increase in postoperative cardiac index and decrease in right ventricular systolic pressure compared with patients who had disease within segmental or distal branch arteries (groups 3 and 4), although this did not achieve statistical significance. We also found that group 1 patients with fresh clot in the main or lobar pulmonary arteries were similar 


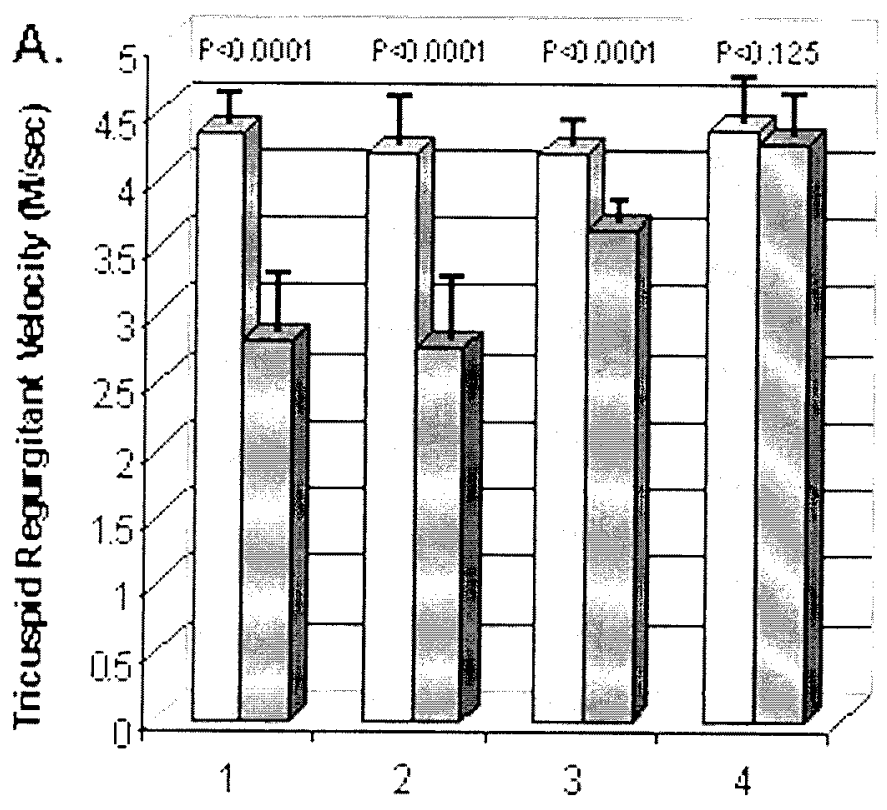

\section{$\square$ Preoperative QPostoperative}

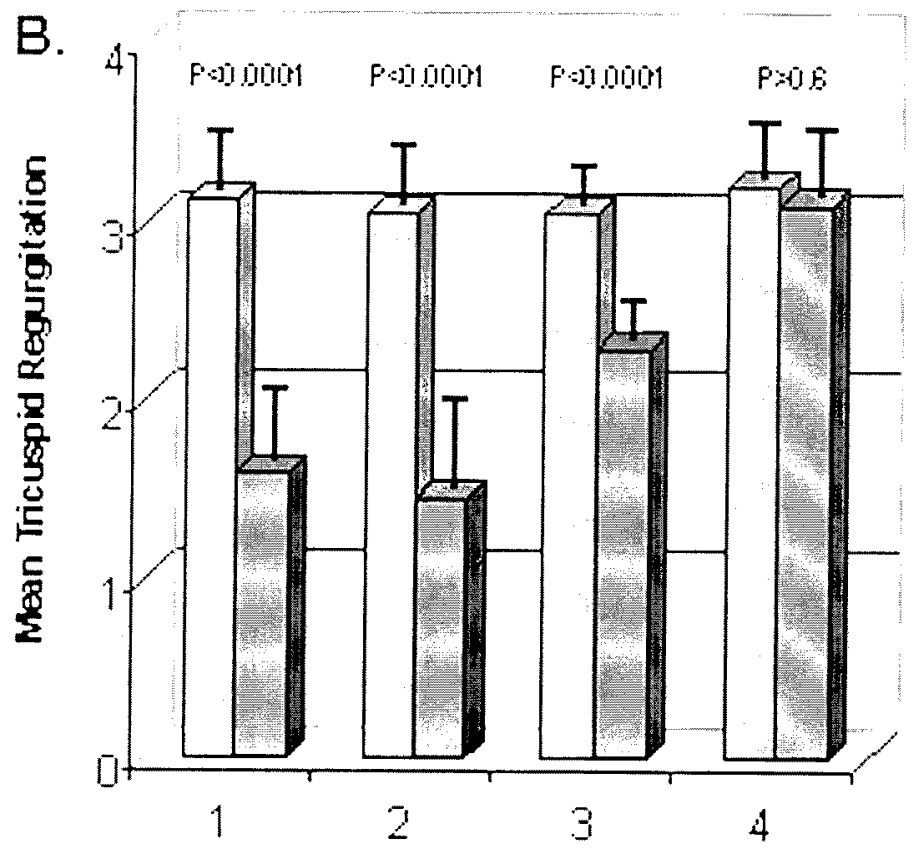

\section{Thromboembolism Classification Group}

Figure 2. Comparison of tricuspid regurgitant jet velocity (A) and graded tricuspid reguirgitation (B) before and after pulmonary endarterectomy. $\boldsymbol{P}$ values express comparisons between preoperative and postoperative values for each thromboembolism classification group. 
TABLE 2. Comparison of perioperative hemodynamic parameters

\begin{tabular}{|c|c|c|c|c|c|}
\hline \multirow[b]{2}{*}{ Variable } & \multicolumn{4}{|c|}{ Thromboembolism classification group } & \multirow[b]{2}{*}{$P$ value } \\
\hline & $\begin{array}{c}1 \\
(n=76)\end{array}$ & $\begin{array}{c}2 \\
(n=81)\end{array}$ & $\begin{array}{c}3 \\
(n=38)\end{array}$ & $\begin{array}{c}4 \\
(n=7)\end{array}$ & \\
\hline Mean decrease in PAS $(\mathrm{mm} \mathrm{Hg})$ & $35.9 \pm 16.3$ & $36.3 \pm 18.2$ & $18.5 \pm 19.4$ & $0.0 \pm 15.6$ & $<.0005$ \\
\hline Mean decrease in PVR (dynes-s-cm ${ }^{-5}$ ) & $661.9 \pm 410.5$ & $565.7 \pm 301.2$ & $244.1 \pm 393.6$ & $260.9 \pm 262.2$ & $<.0005$ \\
\hline Mean increase in $\mathrm{Cl}$ (L/min) & $0.92 \pm 0.40$ & $0.78 \pm 0.50$ & $0.36 \pm 0.37$ & $0.25 \pm 0.34$ & .03 \\
\hline Mean decrease in RVS (mm Hg) & $35.4 \pm 18.4$ & $31.1 \pm 17.4$ & $16.0 \pm 17.1$ & $2.1 \pm 16.2$ & .02 \\
\hline Circulatory arrest time (min) & $37.1 \pm 12.9$ & $35.5 \pm 11.3$ & $42.3 \pm 11.5$ & $34.9 \pm 17.3$ & .04 \\
\hline
\end{tabular}

Data are shown as mean \pm SD or number (percentage).

$P A S$, pulmonary artery systolic pressure; PVR, pulmonary vascular resistance; $C l$, Cardiac index; RVS, right ventricular systolic pressure.

with respect to postoperative hemodynamic outcome (mean decrease in pulmonary artery systolic pressure, pulmonary vascular resistance, and increase in cardiac index) compared with group 2 patients with disease in the same anatomic location but with organized thrombus and intimal fibrosis as the main pathology in the main or lobar pulmonary arteries.

The intraoperative location of thromboembolic disease was a predictor of short-term mortality and hospital length of stay (Table 3). Patients with type 4 disease (distal arterial vasculopathy) had the highest mortality rate of $14.3 \%$ at 1 month after the operation. Although suspected to have thromboembolic disease on the basis of preoperative pulmonary angiography, this small subset of patients had distal vascular disease (ie, primary pulmonary hypertension) without apparent thromboembolism. We found that operations in these patients did little to improve pulmonary vascular resistance or cardiac function. Most (6/7 patients) had persistent postoperative pulmonary hypertension and right heart failure, leading to prolonged inotropic dependence and longer intensive care unit stays.

Patients with type 1 and 2 disease had significantly higher perioperative survival (154/157 [98.1\%] patients) compared with that seen in patients with type 3 and 4 disease (39/45 [86.7\%] patients, $P<.0045$, Table 3$)$ and an overall lower incidence of postoperative complications (Table 4). Atrial fibrillation, pneumonia, and reperfusion pulmonary edema necessitating ventilator dependence for more than 3 postoperative days were the most prevalent complications in each patient group.

Whereas before surgery most patients undergoing pulmonary endarterectomy were in NYHA functional class III, at 3 months' follow-up after the operation, $87.9 \%$ (138/157) of the individuals in groups 1 and 2 were assessed to be in NYHA functional class I or II. These results differ from those seen in patients with type 3 and 4 thromboembolic disease. Most (65.7\%) patients with type 3 or 4 thromboembolic disease were in NYHA functional class III or IV before surgery, with only $30.0 \%$ (9/30 patients) of these same cohorts in NYHA functional class I or II within 3 months after the operation. Of the 7 patients with type 4 disease, only one individual experienced clinical improvement after the operation, with improvement from NYHA functional class III to II symptoms.

\section{Discussion}

Since the first reported successful operation for chronic thromboembolic disease in the lung in $1961,{ }^{13}$ pulmonary endarterectomy has become an established treatment for symptomatic and end-stage pulmonary hypertension. The 5 -year survival for an adult patient diagnosed with pulmonary hypertension resulting from pulmonary embolism has been estimated to be less than 20\%.14 This compares with our institution's 5-year survival after pulmonary endarterectomy of $75 \% .{ }^{15}$ From 1990 to 1999, the UNOS Scientific Registry reported a 78\% 1-month survival and 42\% 5-year survival for single- and double-lung transplantation for pulmonary hypertension and 67\% 1-month survival and 36\% 5-year survival for heart-lung transplantation for pulmonary hypertension. ${ }^{16}$ These results suggest that pulmonary endarterectomy is the treatment of choice for chronic pulmonary thromboembolic disease.

However, despite favorable results in our series of over 1300 pulmonary endarterectomies performed over the last 10 years, ${ }^{17}$ we have come to realize that the disease process resulting from thromboembolic occlusion of branch pulmonary arteries causes a spectrum of vascular disease in the lung. At the time of the operation, a range of distinct pathologies reflecting absorption and remodeling of clot, secondary neointimal changes adjacent to vessels that carry clot, and a distal vasculopathic process remote to the thromboembolic disease have been encountered. We have always been intrigued by the fact that more than $60 \%$ of the patients we operate on with angiographic evidence of main or lobar pulmonary arterial obstruction have no frank clot but rather have secondary intimal thickening and webbing, partially organized thrombus, or both as the cause of the proximal obstruction.

In this study we sought to determine whether the pathologic location and type of disease in the pulmonary arterial tree is a predictor of early postoperative outcome. Our results demon- 
TABLE 3. Postoperative outcome

\begin{tabular}{ccccccc}
\hline $\begin{array}{l}\text { Thromboembolism } \\
\text { classification group }\end{array}$ & Patients & $\begin{array}{c}\text { Median days } \\
\text { intubated }\end{array}$ & $\begin{array}{c}\text { Median days on } \\
\text { inotropic support }\end{array}$ & $\begin{array}{c}\text { Median } \\
\text { ICU days }\end{array}$ & $\begin{array}{c}\text { Median } \\
\text { hospital days }\end{array}$ \\
\hline 1 & 76 & 1 & 1 & 2 & 10 & 98.7 \\
survival (\%)
\end{tabular}

TABLE 4. Perioperative mortality

\begin{tabular}{|c|c|c|c|c|}
\hline \multirow[b]{2}{*}{ Complication } & \multicolumn{4}{|c|}{ Thromboembolism classification group } \\
\hline & $\begin{array}{c}1 \\
\text { (n= } 76) \\
\text { no. of patients } \\
(\%)^{*}\end{array}$ & $\begin{array}{c}2 \\
(n=81) \\
\text { no. of patients } \\
(\%)^{*}\end{array}$ & $\begin{array}{c}3 \\
(n=38) \\
\text { no. of patients } \\
(\%)^{*}\end{array}$ & $\begin{array}{c}4 \\
\text { (n }=7 \text { ) } \\
\text { no. of patients } \\
(\%)^{*}\end{array}$ \\
\hline Reperfusion edema & $15(19.7)$ & $17(21.0)$ & $6(15.8)$ & $1(14.2)$ \\
\hline Atrial fibrillation & $6(7.9)$ & $6(7.4)$ & $15(39.5)$ & $4(57.1)$ \\
\hline Pneumonia & $1(1.3)$ & $3(3.7)$ & $7(18.4)$ & $2(28.6)$ \\
\hline Delirium & $2(2.6)$ & $2(2.5)$ & $3(7.9)$ & $2(28.6)$ \\
\hline Pneumothorax & $1(1.3)$ & $1(1.2)$ & $0(0)$ & $1(14.3)$ \\
\hline Pancreatitis & $0(0)$ & $0(0)$ & $2(5.3)$ & $1(14.3)$ \\
\hline Clostridium difficile colitis/gastrointestinal bleeding & $0(0)$ & $0(0)$ & $2(5.3)$ & $2(28.6)$ \\
\hline
\end{tabular}

*Some patients counted in more than one category.

strate several key points. First, in almost every case, thromboembolic pulmonary hypertension should be considered a bilateral disease. No patient in this study had unilateral thromboembolic pathology, and in our experience of over 1500 total pulmonary endarterectomies, the incidence of unilateral disease has been less than $2 \%$. Indeed, of the 43 patients referred to our institution with unilateral disease since 1986, 16 patients had pulmonary artery sarcoma as the cause of obstruction (unpublished data), ${ }^{18}$ whereas only 27 patients had true unilateral thromboembolic disease. Second, patients with thromboembolic disease proximal to the segmental arteries have the most favorable hemodynamic result from pulmonary endarterectomy, as measured by normalization of pulmonary artery pressures, improvement in pulmonary vascular resistance, and resolution of TR. The pathologic nature of the proximal disease (ie, fresh clot vs organized thrombus vs intimal thickening) did not have any effect on postoperative outcome. This might reflect, in part, that, during the endarterectomy process, all material occluding the vascular lumina, as well as the intima and most of the media, are removed. ${ }^{19}$ Earlier studies by Chow and colleagues ${ }^{20}$ and Dittrich and associates $^{21}$ have suggested that the majority of patients who undergo pulmonary endarterectomy have resolution of pulmonary hypertension, right heart dysfunction, and TR. However, a small subset of patients in most large pulmonary thromboendarterectomy series do not show hemodynamic improvement.9,10,22,23 We have found that the small subset of patients who do not show improvement in TR and right heart function are those with predominantly distal thromboembolic disease. Third, although endarterectomy can be achieved in the segmental pulmonary arteries by means of direct visualization under circulatory arrest, patients with disease limited to this anatomic area have a worse postoperative outcome compared with patients with more proximally located disease. Fourth, a small subset of patients offered pulmonary endarterectomy do not have surgically correctable disease in that the endarterectomy specimen removed from these patients is normal to the level of the distal segmental arteries. These patients' lung biopsy specimens demonstrated a diffuse, small-vessel vasculopathic process of medial hypertrophy and hyperplasia similar to that seen in primary pulmonary hypertension or longstanding mitral disease. ${ }^{24}$ As surgery did not achieve normalization of pulmonary artery pressures or pulmonary vascular resistance in patients with isolated arteriolar and small-vessel disease, this group (type 4 disease) had the highest perioperative mortality, greatest average length of hospitalization, and highest overall incidence of postoperative complications.

Patient age, degree of pulmonary hypertension, and circulatory arrest time have each been identified as multivariable risk factors for early morbidity and mortality in cardiac surgical patients. ${ }^{25-27}$ However, in stratifying patients according to intraoperative thromboembolism classification, we did not find these factors to be associated with hemodynamic improvement or perioperative survival. For all patients in this 3-year cohort, failure to lower pulmonary artery pressure at the time of the operation was most predictive of in-hospital mortality. For all 
classification groups, pneumonia and gastrointestinal complications were the postoperative complications most associated with perioperative death.

Several limitations of this study deserve mention. This analysis is based on an intraoperative assessment of the type and location of thromboembolic disease on the basis of direct observation by the surgeon and by photographic assessment of the pulmonary vascular specimen removed at the time of the operation. We did not perform full-thickness biopsies of different levels of pulmonary vasculature during the endarterectomy procedure because of the inherent risk to the patients in this study. We also did not routinely perform lung biopsy to look for the presence of distal vasculopathic changes, except in those patients with type 4 disease, in whom minimal endarterectomy specimens were recovered. It is our impression from other studies that longstanding proximal pulmonary arterial obstruction might eventually induce small-vessel hypertrophy and hyperplasia through modulation of local mediators, such as angiopoietin 1 and bone morphogenetic protein receptors 1 and 2 (unpublished data). ${ }^{28}$ The influence of arteriolar and capillary pulmonary hypertensive changes in the setting of visible macroscopic thromboembolic disease deserves further study. In addition, approximately one fifth of patients in this study had different types of thromboembolic disease in the right and left lungs. We did not believe that averaging the thromboembolic group (ie, a patient with type 2 disease in the right lung and type 3 disease in the left lung should be considered type 2.5) was a valid way to pool and interpret results. Instead, we considered patients with bilateral disease of 2 different types to be more like the more proximal thromboembolism classification.

In summary, this study demonstrates that intraoperative thromboembolism classification predicts early surgical outcome after pulmonary endarterectomy. We appreciate that cardiac remodeling after pulmonary endarterectomy is not complete in the perioperative period and that our reported results reflect early hemodynamic outcome and survival only. This cohort of patients will be followed over time to determine whether thromboembolism classification will also influence long-term survival and cardiac function. Careful assessment of pulmonary vascular pathology at both gross surgical and microscopic levels should yield further clues as to the biology of pulmonary hypertension and the management of this complex group of patients.

\section{References}

1. Ridel M, Stanek V, Widimsky J, Prerovsky I. Long term follow-up of patients with pulmonary embolism: late prognosis and evolution of hemodynamic and respiratory data. Chest. 1982;81:151-8.

2. Lewczuk J, Piszko P, Jagas J, Porada A, Wojciak S, Sobkowicz B, et al. Prognostic factors in medically treated patients with chronic pulmonary embolism. Chest. 2001;119:818-23.

3. Mo M, Kapelanski DP, Mitruka SN, Auger WR, Fedullo PF, Channick RN, et al. Reoperative pulmonary thromboendarterectomy. Ann Thorac Surg. 1999;68:1770-6.
4. Madani MM, Jamieson SW. Chronic thromboembolic pulmonary hypertension. Curr Treatment Options Cardiovasc Med. 2000;2:141-8.

5. Hirsch AM, Moser KM, Auger WR, Channick RN Fedullo PF. Unilateral pulmonary artery thrombotic occlusion: is distal arteriopathy a consequence? Am J Respir Crit Care Med. 1996;154:491-6.

6. Auger WR, Fedullo PF, Moser KM, Buchbinder M, Peterson KL. Chronic major-vessel thromboembolic pulmonary artery obstruction: appearance at angiography. Radiology. 1992;182:393-8.

7. Jamieson SW, Kapelanski DP. Pulmonary endarterectomy. Curr Prob Surg. 2000;37:165-252.

8. Thistlethwaite PA, Lee SH, Du L, Wolf PL, Sullivan C, Pradhan S, et al. Human angiopoietin gene expression is a marker for severity of pulmonary hypertension in patients undergoing pulmonary thromboendarterectomy. J Thorac Cardiovasc Surg. 2001;122:65-73.

9. Thistlethwaite PA, Auger WR, Madani MM, Pradhan S, Kapelanski DP, Jamieson SW. Pulmonary thromboendarterectomy combined with other cardiac operations: indications, surgical approach, and outcome. Ann Thorac Surg. 2001;72:13-9.

10. Jamieson SW, Auger WR, Fedullo PR, Channick RN, Kriett JM, Tarazi RY, et al. Experience and results with 150 pulmonary thromboendarterectomy operations over a 29-month period. J Thorac Cardiovasc Surg. 1993;106:116-27.

11. Pennestri F, Loperfido F, Salwatori MP, Mongiardo R, Ferrazza A, Guccione P, et al. Assessment of tricuspid reguirgitation by pulsed Doppler ultrasonography of the hepatic veins. Am J Cardiol. 1984; 54:363-8.

12. Yock PG, Popp RL. Noninvasive estimation of right ventricular systolic pressure by Doppler ultrasound in patients with tricuspid regurgitation. Circulation. 1984;70:657-62.

13. Houk VN, Hufnagel CA, McClenathan JE, Moser KM. Chronic thrombotic obstruction of major pulmonary arteries: report of a case successfully treated by thromboendarterectomy and review of the literature. Am J Med. 1963;35:269-82.

14. Van Beek EJ, Kuijer PM, Buller HR, Brandjes DP, Bossuyt PM, ten Cate JW. The clinical course of patients with suspected pulmonary embolism. Arch Intern Med. 1997;157:2593-8.

15. Archibald CJ, Auger WR, Fedullo PF, Channick RN, Kerr KM, Jamieson SW, et al. Long-term outcome after pulmonary thromboendarterectomy. Am J Respir Crit Care Med. 1999;160:523-8.

16. Smith CM, Beasley GC, Cheng Y, Ormond DB, Spain P, editors. 2000 Annual Report: The US Scientific Registry of Transplant Recipients and the Organ Procurement and Transplantation Network: transplant data 1990-1999. (US Department of Health and Human Services, Health Resources and Services Administration, United Network for Organ Sharing, Richmond, Va). 2000. p. 351-410.

17. Jamieson $\mathrm{SW}$, Nomura $\mathrm{K}$. Indications for and the results of pulmonary thromboendarterectomy for thromboembolic pulmonary hypertension. Semin Vasc Surg. 2000;13:236-44.

18. Anderson MB, Kriett JM, Kapelanski DP, Tarazi R, Jamieson SW. Primary pulmonary artery sarcoma: a report of six cases. Ann Thorac Surg. 1995;59:1487-90.

19. Daily PO, Dembitsky WP, Jamieson SW. The evolution and current state of the art of pulmonary thromboendarterectomy. Semin Thorac Cardiovasc Surg. 1999;11:152-63.

20. Chow LC, Dittrich HC, Hoit BD, Moser KM, Nicod PH. Doppler assessment of changes in right-sided cardiac hemodynamics after pulmonary thromboendarterectomy. Am J Cardiol. 1988;61:1092-7.

21. Dittrich HC, McCann HA, Blanchard DG. Cardiac structure and function in chronic thromboembolic pulmonary hypertension. Am J Cardiac Imaging. 1994;8:18-27.

22. Mayer E, Dahm M, Hake U, Schmic FX, Pitton M, Kupferwasser I, et al. Mid-term results of pulmonary thromboendarterectomy for chronic thromboembolic pulmonary hypertension. Ann Thorac Surg. 1996;61: 1788-92.

23. Hartz RS, Byrne JG, Levitsky S, Park J, Rich S. Predictors of mortality in pulmonary thromboendarterectomy. Ann Thorac Surg. 1996; 62:1255-60.

24. Pietra GG, Edward WD, Kay, JM, Rich S, Kernis J, Schloo B, et al. Histopathology of primary pulmonary hypertension. A qualitative and quantitative study of pulmonary blood vessels from 58 patients in the 
National Heart, Lung, and Blood Institute, Primary Pulmonary Hypertension Registry. Circulation. 1989;80:1198-206.

25. Vincens JJ, Temizer D, Post JR, Edmunds LH, Herrmann HC. Longterm outcome of cardiac surgery in patients with mitral stenosis and severe pulmonary hypertension. Circulation. 1995;123:I1137-42.

26. Flameng WJ, Herijgers P, Szecsi J, Sergeant PT. Daenen WJ, Scheys I. Determinants of early and late results of combined valve operations and coronary artery bypass grafting. Ann Thorac Surg. 1996;61:621-8.
27. Roques F, Nashef SA, Michel P, Cortina J, Faichney A, Gams E, et al. Risk factors and outcome in European cardiac surgery: analysis of the Euro-SCORE multinational database of 19030 patients. Eur J Cardiothorac Surg. 1999;15:816-22.

28. Lane KB, Machado RD, Pauciulo MW, Thomson JR, Phillips JA, Loyd JE, et al. Heterozygous germline mutations in BMPR2 encoding a TGF-beta receptor, cause familial primary pulmonary hypertension. The International PPH Consortium. Nat Genet. 2000;26:81-4. 